\title{
Una empresa de Lope de Vega y un soneto de Gómez de Reguera: Nondum erumpit y «Mientras que rompe del oscuro velo»
}

Antonio SÁnchez JimÉnEZ

Université de Neuchâtel

\begin{abstract}
En 1629, Lope de Vega le envió al erudito vallisoletano Francisco Gómez de Reguera un emblema para el rey Felipe IV: Nondum erumpit. Reguera lo incluyó en sus Empresas de los reyes de Castilla y León, que quedó inédito, acompañándolo de un soneto que revela importantes diferencias en cómo los dos escritores entendían la misión de Felipe IV: frente a un Lope mucho más belicista, Reguera proponía un rey pacífico que no necesitaba ejecutar las sombrías amenazas que imaginaba el Fénix, y que gobernaba sobre un país bendecido por los frutos de la paz, en vez de sobre un campo de batalla.
\end{abstract}

Keywords: Lope de Vega, Francisco Gómez de Reguera, Felipe IV, emblemática.

Una de las aficiones más asentadas de Lope, y una pasión que el Fénix compartía con los escritores del momento, fueron las empresas, que sin duda le atraían porque el arte emblemática unía, como él mismo, pintura y poesía. Recordemos que Lope fue uno de los poetas áureos más aficionados a la pintura (Portús Pérez 1999; Sánchez Jiménez 20II), arte que estimaba desde que, como él mismo afirmaba, «nací a sus puertas» (Carducho I633: f. $82 \mathrm{v})^{\mathrm{I}}$. Recordemos también que el Fénix sabía dibujar, como podemos comprobar en los autógrafos de algunas de sus comedias y como afirma en la Jerusalén conquistada (Vega Carpio 2003: 2I), obra en la que, por cierto, dio muestras de esa habilidad con un grabado que retrata a Alfonso VIII y que firma «Lope de Vega Carpio d[elineavit]» (Pérez y Francisco Sánchez Escribano I96I: I45; Portús Pérez I999: I60). Es más, Lope debió de diseñar las estampas que adornan muchas de sus obras -la Arcadia, el Isidro, El peregrino en su patria, las Rimas de Tomé de Burguillos, etc.-, así como los emblemas que incluyó en la Expostulatio Spongiae (Brito Díaz 1996; Portús Pérez 1999: 160). Además, sabemos que el Fénix vivía rodeado de emblemas. Por ejemplo, en su estudio de la calle de Francos tenía un retrato de su hijo Carlos Félix al lado de «una celada que, puesta sobre un libro en una mesa, tenía por alma del cuerpo de esta empresa: Fata sciunt» (Vega Carpio 2015: 227). Asimismo, guardaba allí más alegorías (grabados o dibujos), como una de la Fortuna que le legó al doctor Quintana, u otra que representaba una paloma ensan-

I Lope alude al oficio de su padre, Felices de Vega, que era bordador. 
grentada y que le diseñó Diego de Rómulo con motivo de la muerte de Juana de Guardo (Muguruza, Cavestany \& Sánchez Cantón 1935: 77)². Lope llevó esta afición por los emblemas al terreno profesional, proporcionando alegorías para la entrada de Isabel de Borbón en Madrid en I6II y para las justas de beatificación y canonización de san Isidro, en I620 y I622 (Brito Díaz 1996: 356 y 358). Como cabría esperar, este amor por las empresas no dejó de influir en su obra, en una fecunda relación que han explorado diversos estudiosos (Moir 197I; Dixon 1982; Dixon 1992; Martínez 1994; Calvo 2005; Lorenzo Domínguez 2017).

Menos conocida es su faceta de emblemista espontáneo de la casa de Austria, para la que ideó varias empresas entre las que destaca «Nondum erumpit», que diseñó en I629 para Francisco [Gómez] de la Reguera y sus Emblemas de los reyes de Castilla y de León. El presente trabajo repasa las circunstancias en que Lope compuso este emblema, centrándose en estudiar la relación de la empresa con el soneto que escribió Reguera para acompañarlo. Este análisis servirá para establecer un contraste entre las ideas que Reguera albergaba sobre Felipe IV y las que tenía el Fénix, oposición que ilustraremos con la empresa y con algunos textos panegíricos que compuso Lope para la niñez de Felipe III y Baltasar Carlos, así como para la subida al trono del propio Rey Planeta.

Sabemos por el códice Durán que Lope ideó tres empresas para los Habsburgo, entre ellas «un rayo coronado cercado de una nube y la letra Nondum erumpit» (Vega Carpio 20II: 5II). Parece que trabajó en ellas a petición del escritor vallisoletano Francisco de la Reguera (1594 o 1599-I673), gentilhombre de cámara del cardenal infante don Fernando y escritor de gran cultura humanística (González de Olmedo 1919a y 1919b; Grigoriadu 2006; Grigoriadu 20II; Pena Sueiro 2009: 344). El propio Reguera explica en el libro las circunstancias en que recibió la empresa lopesca en I629:

Debo esta empresa al felicísimo ingenio, fénix de España, Lope de Vega Carpio, que habiéndole comunicado este trabajo para que lo enmendase, y diese noticias de algunas empresas de nuestros reyes, a que no llegó la mía, pidiéndole en particular si el rey nuestro señor Felipe Cuarto había usado alguna; que aunque en una medalla del retrato de su Majestad que hizo el caballero Rutilo, con la excelencia con que ejecutó otras muchas cosas, estaba en el reverso el carro del sol con la letra Iam illustrabit omnia, que es la mesma que usó el señor rey D. Felipe Segundo, como vimos arriba, no me pareció ponerla aquí por no repetir una misma cosa. Y así me escribió con particulares estimaciones y alabanzas de lo escrito y ejecutado en estos cuadernos, que estimé por favores de quien también sabía honrar aun a los más cortos ingenios, como el mío. Pero que no sabía hubiese su Majestad usado alguna, como las usaron los señores reyes sus progenitores. Y así, para que

2 Rómulo le proporcionó otros emblemas que reseña Brito Díaz (1996:358). 
pusiese entre estas, me envió la presente, que había hecho a su Majestad, considerando su poder y la viveza y actividad de su real espíritu, y que hasta entonces, que fue el año de mil seiscientos veinte y nueve, su Majestad no había salido a facción militar, pareciéndole que en el rayo dentro de la nube se decía todo, pues en sí mismo encierra la actividad y poder, que sola la ejecución faltaba, pues aún no había roto la nube que le retenía: Nondum erumpit. Este rayo pintó Apeles a Alejandro encareciendo Pierio Valeriano el jeroglífico 3 .

No he querido hacer más discurso que su mismo diconcepto y palabras, pues no podré adelantar más yo lo que él pensó también. Solo añadí el soneto y le remití con debidos agradecimientos. $Y$ si los poetas son vates, quisiera saliese verdadero este vaticinio, y siendo su Majestad rayo, triunfase con mil victorias de sus enemigos (Reguera I990: 252).

Tanto Lope como Manuel de Faria y Sousa incitaron a Reguera a imprimir el libro, que estaría acabado ya hacia I632 (Reguera I990: 55). Sin embargo, el volumen languideció tras la muerte del cardenal infante, que había sido el impulsor del proyecto, y quedó inédito tras la desaparición del propio Reguera (Hernández Alonso I990: I2). El libro, las Empresas de los reyes de Castilla y de León, permaneció, pues, manuscrito, aunque en I678 lo preparó para la imprenta el padre fray Tomás de Llamazares (Hernández Alonso I990: I). El volumen fue luego copiado diversas veces hasta llegar a las prensas a finales del siglo xx (Pena Sueiro 2009).

El interés literario del libro es modesto, aunque destaca en él la última empresa que le añadió Reguera, el «Nondum erumpit» que constituye uno de los escasos ejemplos que conservamos de la faceta de Lope como emblemista. La imago que diseñó el vallisoletano sobre el motto lopesco es fiel, aunque añade algunos elementos que solo se pueden deducir de una lectura muy amplia de la idea del Fénix. Nos referimos a los frutos en las esquinas inferiores, que simbolizan la feracidad de la paz y que, como veremos abajo, Reguera incluye también en su poema, aunque bajo forma de la alusión final al arco iris y la paz.

3 Reguera se refiere a una anécdota que trae Pierio Valeriano (I685: 55I). 


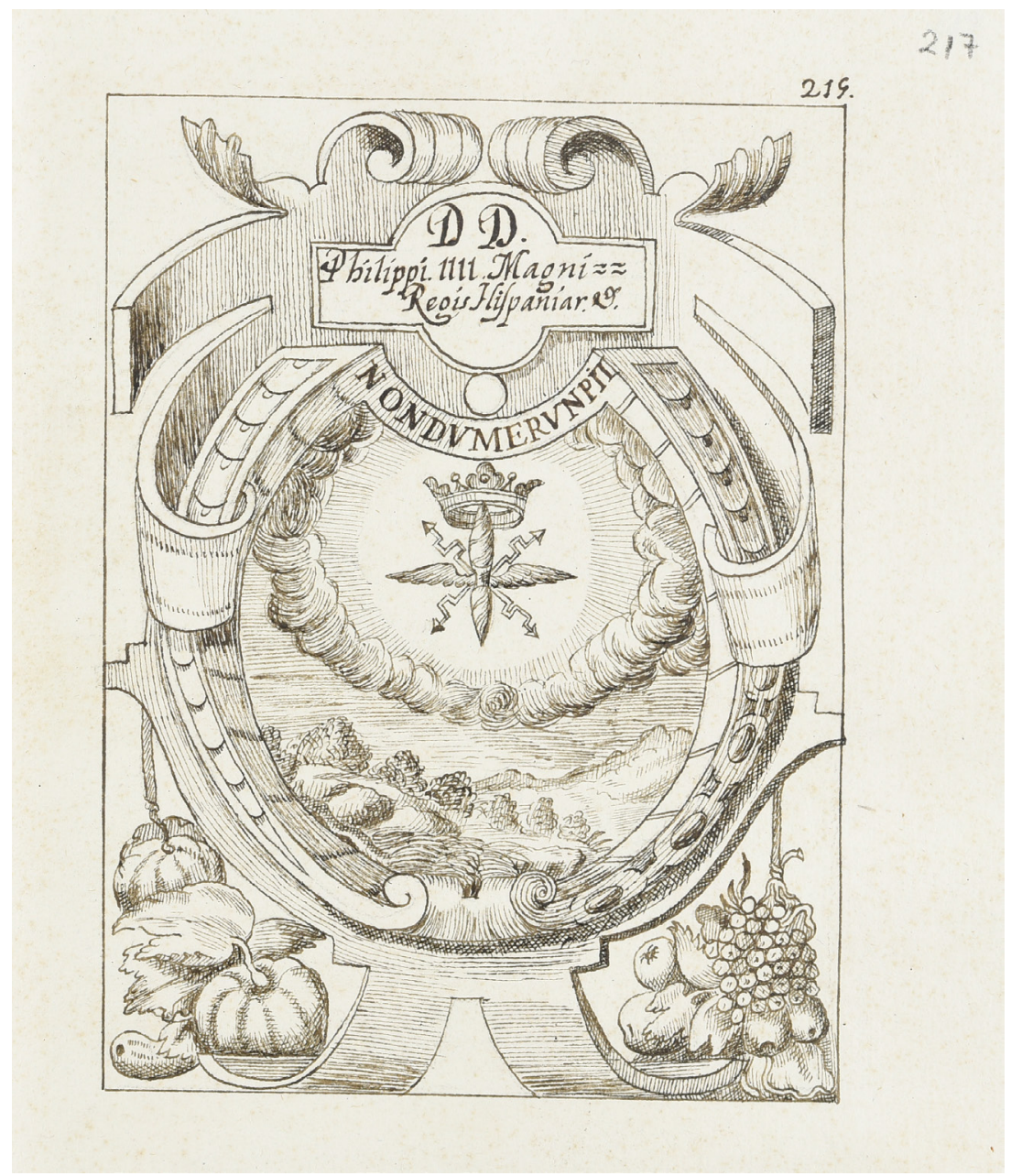

Mss. I748I BNE

Como hemos adelantado, y como afirma Reguera en el texto que hemos citado arriba, el emblema viene acompañado de un soneto obra del vallisoletano: 
Mientraf que rompe del obfarro velo, la deuil carcel; mientras oprimido, (alma ya de vna nube) e) detenido, el vayo en fom bras con prifíon de bielo;

Quando parece que piadofo el juclo, feniega, en fu piedad aun ef temido, defde el pintado pajaro en ju nido. almonie que obelifco a falta el Cielo;

Alienta pue/ entu flovida epbera, enocio el brio con la deuil caña. que rayo al mundo tu valov le eppera; Sevà atu nombre la mayor bazaria, que tema mas, quien maj te confidera, blanda eftrella de amor, Ivis de eppaña.

Mss. I748I BNE

Transcrito, modernizado y puntuado, el texto es el siguiente:

Mientras que rompe del oscuro velo

la débil cárcel, mientras oprimido

-alma ya de una nube- es detenido

el rayo en sombras con prisión de hielo; 
cuando parece que, piadoso, el suelo se niega, en su piedad aun es temido, desde el pintado pájaro en su nido al monte que, obelisco, asalta el cielo,

alienta, pues, en tu florida esfera en ocio el brío con la débil caña, que rayo al mundo tu valor le espera.

Será a tu nombre la mayor hazaña que tema más quien más te considera, blanda estrella de amor, Iris de España.

Es un buen ejemplo del estilo de Reguera, cuya obra poética alaba Lope en el Laurel de Apolo (Vega Carpio 2008: silva III, vv. 337-349). Según fray Tomás Llamazares el Fénix solía incluso afirmar que «no había poeta en España que cerrase un soneto con la gracia que D. Francisco de la Reguera» (Reguera 1990: 56). Pese al entusiasmo panegírico del Laurel y del padre Llamazares, debemos reconocer que el poema que nos ocupa no responde a esas expectativas. Es así por motivos de estilo, pero también por unos muy interesantes contrastes temáticos que vamos a explicar en el resto del presente artículo.

La estructura del texto de Reguera es claramente bipartita, con dos cuartetos en los cuales el vallisoletano pinta un amenazador estado de inminencia. El primero presenta la imagen del rayo encerrado en la nube, que Reguera describe con términos que sugieren un parto. Por su parte, el segundo cuarteto pinta la reacción del mundo cuando entiende que el rayo se ha compadecido de él y se ha decidido a permanecer en la nube, en vez de dar rienda suelta a su poder destructivo. En los tercetos, estos símbolos adquieren un referente concreto mediante la apelación a Felipe IV. En ellos reaparece el rayo de los primeros versos envuelto en imágenes de juventud («florida esfera»), aunque esta vez Reguera presenta el elemento amenazante transformado en una frágil caña que esgrime el monarca y que solo es percibida como rayo por el temor del mundo, consciente del valor y fuerza del rey hispano. El concepto final del soneto incide en este respeto, que resulta mayor en aquellos que con más atención contemplan la temible nube preñada de rayos que representa a Felipe (vv. I2-I3). En el último verso, Reguera acaba describiendo al monarca con imágenes de paz. Manteniéndose en el campo semántico celeste que domina el poema, la nube amenazadora se revela una estrella de paz y un benéfico arco iris que anuncia el final de la tormenta.

La glosa arriba citada nos deja ver que Reguera entendió perfectamente la empresa de Lope como una amenaza contra los enemigos de España. El emblema era una promesa de destrucción de estos contrarios a manos de un 
Felipe IV que en I629 aún no había salido a campaña, pero que tenía ejércitos inmersos en la guerra contra las Provincias Unidas (la tregua había expirado justo a comienzos de su reinado, en I62I) y en la guerra de los Treinta Años, enfrentamientos que provocaban crecientes tensiones con Francia que desembocarían, en I635, en una guerra abierta con el país vecino. Para Lope, la empresa personal de Felipe IV era un augurio de actividad bélica inminente: «su Majestad no había salido a facción militar, pareciéndole que en el rayo dentro de la nube se decía todo, pues en sí mismo encierra la actividad y poder, que sola la ejecución faltaba, pues aún no había roto la nube que le retenía» (Reguera I990: 252).

Sin embargo, y pese a explicar el sentido del lema lopesco en la declaración en prosa, el cabo del soneto de Reguera le imprime a la imagen una dirección muy diferente que resulta aparentemente impropia por contrastar con los cuartetos y con el contexto de I629. La primera presunta impropiedad, la textual, se puede explicar parcialmente por influencia de una imagen muy habitual en panegíricos lopescos dirigidos a niños de la familia real. Nos referimos a la mención de la caña en el v. Io del soneto de Reguera: «alienta, pues, en tu florida esfera / el ocio en brío con la débil caña» (vv. 9-Io), que parece una alusión al juego de cañas. En lugar de esgrimir una lanza (metafóricamente, el rayo), el monarca divierte sus ocios con la caña, simulacro de un asta bélica. Sin embargo, la caña no era solamente el liviano venablo del juego de cañas, sino también un juguete infantil al que alude Covarrubias: «los niños hacen unos caballitos de cañas, en los cuales todos dimos nuestras carreritas, hicimos casillas de tejuelas y armamos carretillas de corcho, y jugamos a pares y nones» (Covarrubias Orozco 2006: s. v. caña). De hecho, Lope solía referirse a este juguete cuando quería aludir a la niñez de un príncipe. Es el caso del soneto CXCIII, «A la encamisada del príncipe, nuestro señor», de las Rimas, texto en que el Fénix imagina a Felipe III como un aguilucho que demuestra su sangre real mirando al sol de frente mientras se prepara para recibir la herencia de su padre:

\footnotetext{
Muestra, subido al cielo, al baxo mundo las nuevas uñas con que alçar le puedes, agora asidas de una débil caña.

Porque tercero de tan gran segundo, podrás, como su espada y cetro heredes, vencer el mundo y governar a España (Vega Carpio I994: I, 607, vv. 9-I4).
}

Y también es el caso de un soneto que precisamente data de i629, el que Lope dedica «Al nacimiento del Príncipe, nuestro señor» y que luego publi- 
có en las Rimas de Tomé de Burguillos. En él los tercetos vuelven a presentar la imagen de la caña infantil:
Indias y amores os ofrece España;
y yo os ofrezco a falta de tesoros
un caballito, regilero y caña,
con que podáis después (no digo toros,
que siendo Carlos, es su propia hazaña)
correr los gallos y matar los moros
(Vega Carpio 2002: núm. 89, vv. 9-I4).

Si estas cañas lopescas remiten claramente a la niñez ${ }^{4}$, la de Reguera no apunta a ese periodo de la vida, pues su soneto está dirigido al Felipe IV de I629, un joven de veinticuatro años que se encuentra, pues, en su «florida esfera» [v. 8]. No obstante, la agresividad de los cuartetos inspirados en la empresa de Lope contrasta con las imágenes finales del soneto de Reguera -«débil caña» incluida-, que rezuman suavidad e, incluso, pacifismo: el temible rayo se transforma en el verso final en una «blanda estrella de amor» y en un arco iris, imágenes no solo amables, sino incluso más habituales para describir un niño o una dama (Iris es una diosa) que a un soberano. De hecho, estas imágenes no solo contrastan con los cuartetos, sino también con el contexto de i629: con los afanes bélicos que albergaba Felipe IV y con el entusiasmo marcial con que muchos acogieron su subida al trono. Valga como ejemplo de este tono el soneto «Cuando heredó su Majestad estos reinos intentó escribir de veras», de las Rimas de Tomé de Burguillos, en el que Lope saluda al nuevo monarca como el estímulo que necesitaban los practicantes de las armas y las letras en el país:

Purpúreo Febo, despreciando el suelo, a sí mismo fatal se anochecía, cuando con plumas de oro el Fénix día previno a España el generoso vuelo.

El peso del Atlántico desvelo en dos altos pirámides confía, en quien pudo librar su monarquía, por bien universal, piadoso el cielo.

Salió de la ignorancia y los agravios el imperio a la ciencia, y persuadida la fama a la verdad doró los labios.

4 A ellas debemos añadir la de un soneto de la Corona trágica (Vega Carpio 2014: 53I). 
Hable la guerra y el estudio pida; tendrán en el gobierno de los sabios, laurel las armas, y las letras vida (Vega Carpio 2002: núm. I42).

El mensaje que presenta el soneto de Reguera no puede ser más diferente de las esperanzas que albergaba Lope en I62I y que delata este soneto del Burguillos.

En suma, la empresa «Nondum erumpit» es un interesante ejemplo de dos tipos de contraste: el que opone las ideas políticas de dos amigos como Lope y Reguera, por una parte, y, por otra, el que enfrenta entre sí las diversas partes de un emblema (su figura e inscriptio frente al epigrama), e incluso las diversas partes de un poema, el soneto de Reguera. Estos enfrentamientos textuales surgieron porque Lope le envió a Reguera un emblema con cuyo espíritu el vallisoletano debía de estar en desacuerdo, aunque este sentimiento pesaba en su ánimo menos que el respeto y aprecio que le infundía el Fénix. Por ello, el autor de las Empresas de los reyes de Castilla y León incluyó en el libro la empresa que le proponía Lope, e incluso la glosó dando claras muestras de entenderla. Sin embargo, también la completó escribiendo para ella el soneto «Mientras que rompe del oscuro velo», y en ese texto Reguera reorienta el énfasis virulento de la idea del Fénix desarrollando un concepto que solo existía en potencia en la empresa de Lope: a ojos del vallisoletano, Felipe IV no era una nube ceñuda, sino piadosa, una nube que había elegido controlar su poder destructor y convertirse en una fuerza benéfica que anunciaba la paz que tanto necesitaba la Monarquía Hispánica. A la altura de I629, cuando Europa se arrojaba a una conflagración continental que sellaría el declive de los Habsburgo españoles, el mensaje del soneto de Reguera se antoja moderado, incluso pacifista. A su ver, Felipe IV debía ser una «blanda estrella de amor»e «Iris de España» al que sus amigos temieran sin necesidad de enfrentarse a él.

\section{Bibliografía}

Brito Díaz, Carlos, «"Odore enecat suo”: Lope de Vega y los emblemas», en Literatura emblemática hispánica: actas del I simposio internacional, ed. S. López Poza, A Coruña, Universidade da Coruña, 1996, pp. 355-377.

Calvo, Florencia, «Teatro y emblemática: Favila y los modelos de gobernantes en el teatro histórico de Lope de Vega», en Estudios de Teatro Español y Novohispano: Actas del XI Congreso de la Asociación Internacional de Teatro Español y Novohispano de los Siglos de Oro (septiembre 2003, Buenos Aires), Buenos Aires, Universidad de Buenos Aires, Facultad de Filología y Literaturas Hispánicas, 2005, pp. 139-I52. 
Carducho, Vicencio, Diálogos de la pintura, su defensa, origen, esencia, definición, modos y diferencias, Madrid, Francisco Martínez, I633.

Covarrubias Orozco, Sebastián de, Tesoro de la lengua castellana o española, Ed. I. Arellano y R. Zafra, Madrid, Iberoamericana, 2006.

Dixon, Victor, “"Beatus... nemo”: El villano en su rincón, las “polianteas” y la literatura de emblemas», Cuadernos de Filología, 3.I-2, I982, pp. 279-300.

-. «The Emblemas morales of Sebastián Covarrubias and the Plays of Lope de Vega», Emblematica: An Interdisciplinary Journal of Emblem Studies, 6.I, I992, pp. 83-IOI.

González de Olmedo, Félix, «Un gran artista vallisoletano desconocido», Razón y Fe, 54, I9I9, pp. 356-364, y pp. 46I-467.

—. «Un gran artista vallisoletano desconocido», Razón y Fe, 55, I9I9, pp. 8388.

Grigoriadu, Teodora, «Francisco de la Reguera: un traductor más y único continuador de Luciano de Samósata en el Siglo de Oro», Cuadernos de Filología Clásica: estudios griegos e indoeuropeos, I6, 2006, pp. I8I-I93.

-. "Libro terzero de las Historias Verdaderas de Luciano, escritas en lengua castellana por don Francisco de la Reguera, natural de Valladolid: estudio y edición de la única continuación literaria de Luciano de Samósata en el Siglo de Oro», Criticón, II3, 20II, pp. II9-I5I.

Hernández Alonso, C. (ed.), Francisco de la Reguera, Empresas de los reyes de Castilla y León, Valladolid, Universidad de Valladolid, I990.

Lorenzo Domínguez, Javier, «Una adelfa en tierras extrañas: emblemática y misoginia en la Comedia famosa de los guanches de Tenerife y conquista de Canaria», Anuario Lope de Vega. Texto, literatura, cultura, 23, 2017, pp. 484498.

Martínez, Christine, «Disguised Discourse: Emblems in Lope de Vega's El castigo sin venganza», Bulletin of the Comediantes, 46.2, I994, pp. 207-217.

Moir, Duncan, «Lope de Vega's Fuenteovejuna and the Emblemas morales of Sebastián de Covarrubias Horozco (with a Few Remarks on El villano en su rincón)», en Homenaje a William L. Fichter. Estudios sobre el teatro antiguo hispánico y otros ensayos, eds. A.D. Kossoff y J. Amor y Vázquez, Madrid, Castalia, I97I, pp. 537-546.

Muguruza, P., J. Cavestany \& F. J. Sánchez Cantón, «Noticia sobre la reconstrucción de la casa de Lope», en La casa de Lope de Vega, Madrid, Centro de Estudios Históricos, I935, pp. 19-80.

Pena Sueiro, Nieves, «Las Empresas de los reyes de Castilla de Francisco Gómez de la Reguera a la luz de un nuevo testimonio», Boletín de la Real Academia Española, 89, 2009, pp. 343-363.

Pérez, L. C. \& Francisco Sánchez Escribano, Afirmaciones de Lope de Vega sobre preceptiva dramática, Madrid, Consejo Superior de Investigaciones Científicas, 196I. 
Reguera, Francisco de la, Empresas de los reyes de Castilla y León, ed. C. Hernández Alonso, Valladolid, Universidad de Valladolid, 1990.

Valeriano, Pierio, Hieroglyphica, Colonia, Ioannem Wilhelmum Friessem, 1685.

Portús Pérez, Javier, Pintura y pensamiento en la España de Lope de Vega, Hondarribia, Nerea, 1999.

Sánchez Jiménez, Antonio, El pincel y el Fénix: pintura y literatura en la obra de Lope de Vega Carpio, Madrid, Iberoamericana, 2011.

Vega Carpio, Lope de, Rimas, ed. F. B. Pedraza Jiménez, 2 vols., Ciudad Real, Universidad de Castilla-La Mancha, 1994.

-. Rimas humanas y divinas del licenciado Tomé de Burguillos, ed. A. Carreño, Salamanca, Almar, 2002.

-. Jerusalén conquistada. Epopeya trágica, dd. A. Carreño, Madrid, Biblioteca Castro, 2003.

—. Laurel de Apolo, dd. A. Carreño, Madrid, Cátedra, 2008.

-. Códice Durán-Masaveu, eds. A. Madroñal Durán et al., Asturias, Real Academia Española, 20II.

-. Corona trágica, eds. Antonio Carreño-Rodríguez y Antonio Carreño, Madrid, Cátedra, 2014.

-. El verdadero amante, en Comedias de Lope de Vega. Parte XIV, ed. E. Rodríguez, coord. J. E. López Martínez, vol. 2, Madrid, Gredos, 2015, pp. 20I378. 